\title{
The communication of physical science uncertainty in European National Adaptation Strategies
}

\author{
S. Lorenz • S. Dessai • J. Paavola • P. M. Forster
}

Received: 11 January 2013 / Accepted: 24 May 2013 / Published online: 27 July 2013

(C) The Author(s) 2013. This article is published with open access at Springerlink.com

\begin{abstract}
Many European countries have developed National Adaptation Strategies (NAS) to guide adaptation to the expected impacts of climate change. There is a need for more structured communication of the uncertainties related to future climate and its impacts so that adaptation actions can be planned and implemented effectively and efficiently. We develop a novel uncertainty assessment framework for comparing approaches to the inclusion and communication of physical science uncertainty, and use it to analyse ten European NAS. The framework is based on but modifies and integrates the notion of the "cascade of uncertainties" and the NUSAP (Numeral Unit Spread Assessment Pedigree) methodology to include the overarching assessment categories of Numerical Value, Spread, Depth and Substantiation. Our assessment indicates that there are marked differences between the NAS in terms of inclusion and communication of physical science uncertainty. We find that there is a bias towards the communication of quantitative uncertainties as opposed to qualitative uncertainties. Through the examination of the English and German NAS, we find that similar stages of development in adaptation policy planning can nevertheless result in differences in handling physical science uncertainty. We propose that the degree of transparency and openness on physical science uncertainty is linked to the wider socio-political context within which the NAS are framed. Our methodology can help raise awareness among NAS users about the explicit and embedded information on physical science uncertainty within the existing NAS and would help to design more structured uncertainty communication in new or revised NAS.
\end{abstract}

\section{Introduction}

During the past decade, climate change adaptation has gained importance on the climate change policy agenda and since 2005 a number of European countries have published their

This article is part of a Special Issue on "Managing Uncertainty in Predictions of Climate and Its Impacts" edited by Andrew Challinor and Chris Ferro.

Electronic supplementary material The online version of this article (doi:10.1007/s10584-013-0809-1) contains supplementary material, which is available to authorized users.

S. Lorenz $(\bowtie) \cdot$ S. Dessai $\cdot$ J. Paavola $\cdot$ P. M. Forster

School of Earth and Environment and Centre for Climate Change Economics and Policy, University of Leeds, Leeds LS2 9JT, UK

e-mail: ee08s1@leeds.ac.uk 
National Adaptation Strategies (NAS). It has been recognised that due to the inertia in the climate system, Europe and the rest of the world will experience substantial climate change and related impacts even if stringent mitigation targets are set and achieved. Therefore, understanding the risks of climate change (and adaptation) and uncertainties associated with them is important.

In Europe adaptation efforts are guided by the adaptation framework (Commission of the European Communities 2009) developed by the European Union (EU), which aims to establish a European adaptation strategy and to encourage greater coordination and integration of adaptation across its member states. The framework encourages, but does not mandate, member states to prepare and implement their own NAS. Several studies have examined aspects of climate change adaptation in Europe (e.g. Hanger et al. 2012; Juhola and Westerhoff 2011; Termeer et al. 2012). Studies of NAS have typically focused on their content, context of their development, their dissemination, policy integration, and monitoring and evaluation (Biesbroek et al. 2010; Swart et al. 2009). The question of how different countries deal with uncertainty within adaptation planning (Hanger et al. 2012) and the role and inclusion of scientific information and uncertainty in NAS has sometimes been addressed (Biesbroek et al. 2010), though no detailed analysis has been conducted on the inclusion and communication of physical science uncertainty and potential variations between them across countries.

Traditionally, risk communication was considered to improve understanding of the world people live in and the risks they face (Fischhoff 1987). In the area of climate change, the risks people face, however, can be geographically and temporally removed and somewhat mismatched with necessary actions. Therefore, there is a need for scientists to provide usable information on the risks associated with climate change and its impacts to inform the decision-making process (Pidgeon 2012). Ad-hoc communication cannot be relied on to address this high-stake problem: a more structured and organized approach is needed (Fischhoff 2011).

There are many uncertainties related to climate change and many studies have tried to classify them (e.g. Curry and Webster 2011; Dessai and Hulme 2004; Stainforth et al. 2007). The communication of uncertainty is thus becoming an increasingly debated subject (e.g. Budescu et al. 2009; Fischhoff 2007; Moser and Dilling 2011; Rabinovich and Morton 2012). A key finding of this research is that a 'one-size-fits-all' approach to communication does not yield a desired response. Audience-specific communication (Moser and Dilling 2011) and an awareness of the fact that the production and processing of knowledge are deeply rooted within the practices and traditions of individual countries (Jasanoff 2011) are needed.

A number of studies have examined the link between adaptation planning and decisionmaking on the one hand and uncertainty on the other hand (e.g. Dessai and van der Sluijs 2007). This research has focused on mapping and matching theoretical methods, tools and decision frameworks on adaptation and uncertainty in the policy making sphere. That is, they have focused on the link between the two in the theoretical process of decision-making. We propose to examine empirically to what extent scientific uncertainty is considered and communicated in the outcomes of these processes, such as in the National Adaptation Strategies, by using a novel uncertainty assessment framework.

There is an increasing demand for coordinated uncertainty communication in the adaptation field (Lourenço et al. 2009). For this demand to be met, we need to gain a better understanding as to how uncertainty is currently communicated within the relevant policy contexts. However, it has to date not been studied to what extent the different European NAS consider and communicate scientific uncertainty, even though they are the most important currently existing policy documents in Europe, aiming to provide decision-relevant information for national adaptation planning. By analysing them, we can consider a central question that arises from existing research in an empirical way: Considering that substantial 
uncertainties do exist regarding climate change and adaptation, to what extent are they communicated transparently in the NAS? This paper presents an uncertainty assessment framework which provides a tool to compare the different levels of information disclosed on scientific uncertainty in the NAS. The insights gained from this research will be useful in both the development of NAS and will also add an extra dimension to the knowledge base for the European Adaptation strategy.

In what follows, we will first analyse how NAS communicate their scientific underpinnings. We then introduce an uncertainty assessment framework based on the integration of the notion of the "cascade of uncertainty" (e.g. Schneider 1983; Wilby and Dessai 2010) and a modification of the NUSAP (Numeral Unit Spread Assessment Pedigree) methodology (Funtowicz and Ravetz 1990; van der Sluijs et al. 2005a, b). This framework enables us to assess and compare the NAS in terms of how they include and communicate physical science uncertainty. Secondly, seen that the communication approaches are clearly distinct in the different NAS, we use the British (focusing on England) and German cases to take a first step towards exploring some of the broader policy contexts and socio-political factors that form the context and influence the development process of the NAS. This excursus is suggestive of how differences in uncertainty communication practices across countries cannot be explained by the state of the knowledge base, the stage of adaptation planning or the institutional context alone, they also relate to country-specific socio-political frameworks; a finding which opens an interesting avenue for further research.

\section{Methodology}

We employed qualitative content analysis in a systematic review of the coverage of physical science uncertainty in the NAS. Most countries plan to publish both NAS (overarching guidance document) and National Adaptation Plans (outline of specific adaptive measures and delivery responsibility). By June 2012, 14 NAS had been adopted in Europe. Of these, we have considered only those available in English. These are the NAS for: Belgium, Denmark, England, Finland, France, Germany, Hungary, Netherlands, Scotland and Wales (see Table A in Online Resource 1 for more details on these NAS. The NAS of Scotland, Wales and England are considered separately because of the UK's devolved legal system). ${ }^{1}$ The progress and implementation of the adaptation strategy and delivery frameworks vary across countries and their strategies vary substantially in terms of their level of detail. Yet they can be considered sufficiently comparable in all important respects.

We developed a novel uncertainty assessment framework for comparing the different countries' approaches to the inclusion and communication of physical science uncertainty. The framework is based on the integration and modification of the concept of the "cascade of uncertainties" and the NUSAP methodology (see Fig. 1 for the conceptualisation of the framework). The NUSAP method (Funtowicz and Ravetz 1990; van der Sluijs et al. 2005b) was originally designed to combine quantitative assessments of uncertainty (the Numeral, its Unit and the Spread) with qualitative judgements (Assessment and Pedigree). It thus allows for a systematic consideration of the different dimensions of uncertainty (van der Sluijs et al. 2005b).

Our uncertainty assessment framework considers Numerical values (Do strategies assign numbers to the climate projections and uncertainties they mention?), Spread (Do strategies use ranges to convey the climate information rather than one deterministic number?), Substantiation (To what extent are NAS transparent about the foundation of the science

\footnotetext{
${ }^{1}$ To date Northern Ireland does not have a NAS and can thus not be included.
} 


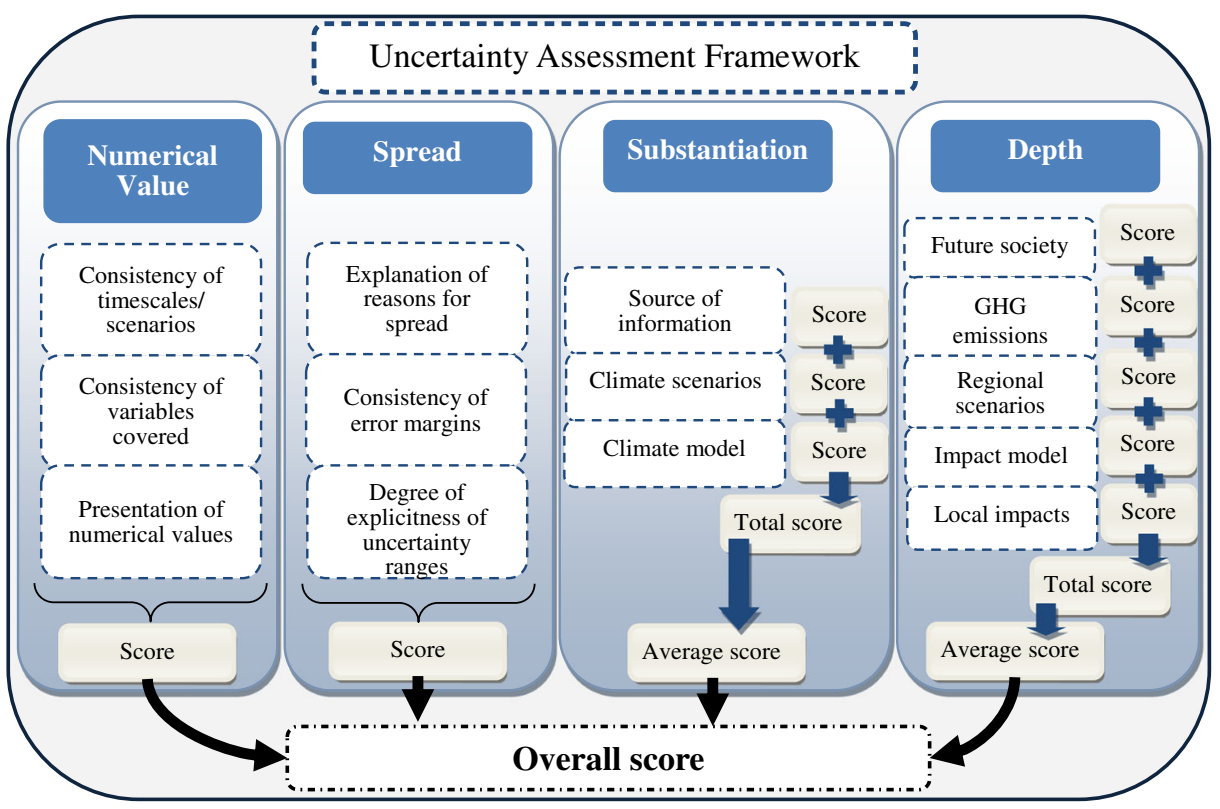

Fig. 1 The uncertainty assessment framework. The figure conceptualises the Uncertainty Assessment Framework which is based on the integration and modification of the NUSAP methodology and the idea of the cascade of uncertainty

communicated within them?) and Depth (To what extent do NAS take account of the various sources of uncertainty using the outcomes from the cascade of uncertainties?). Substantiation was assessed in terms of source of information (extent of references to other information sources within NAS), climate scenario (extent and clarity of specific information on climate scenario used) and model projections (level of explicitness about which climate model was used to create projections in NAS).

Each category was scored to facilitate comparison as follows: 2 Points - information has been included in detail in the strategy, 1 Point - required information for a given category has been mentioned, but without further detail or explanations possibly also containing inconsistencies or lack of clarity. 0 Points - no information at all has been provided. The scores were then averaged firstly for the three criteria under Substantiation and then for all of the four main categories of the framework to generate an overall score for each NAS. Depth incorporates the concept of the cascade of uncertainty as described by Wilby and Dessai (2010) which helps to assess identified sources of uncertainties in the NAS. The uncertainties multiply as they pervade different levels of the cascade from future society, greenhouse gas (GHG) emissions, climate model, regional scenario, impact model, local impacts to adaptation responses (Wilby and Dessai 2010). We omitted the final level in the cascade, adaptation responses, as they will be more central to the National Adaptation Plans than to the NAS.

The cascade of uncertainty draws attention to the multitude of uncertainties that affect the climate adaptation planning and delivery process. It is thus a useful tool to assess to what extent the NAS are explicit about the different uncertainties present. We used a scoring system (explained below) to facilitate the comparison of NAS. Scores were given for each source of uncertainty and an average score calculated for each NAS. 


\section{Results - the inclusion or exclusion of science and uncertainty}

Before analysing in detail the communication of scientific uncertainty, a number of more general observations on the communication of science in the NAS can be made. Firstly, there is a tendency to communicate physical science in the text of the NAS, rather than by using visual means such as graphs, tables or figures. Different countries communicate projections differently in text, some using numbers with or without decimal points, others using ranges rather than absolute numbers, and still others using proxy statements (e.g. number of frost days (Finnish NAS) or not quantifying statements at all) "more mild winters and hot summers" (Dutch NAS).

Visual communication of science also varies substantially in the NAS. For instance, the NAS of Scotland explicitly explains how to understand the used probabilistic projections whereas the NAS of Germany uses graphs in a similar way as the Intergovernmental Panel on Climate Change (IPCC) does in its Assessment Reports without detailed explanation. These different choices regarding visual communication may be indicative of different expectations placed on the audience, and different contextual frameworks within which these strategies have been developed.

There are also marked differences in the coverage of uncertainty between countries. Germany and the Netherlands mention uncertainty more than the other NAS. However, the acknowledgement of uncertainty itself often does not result in the provision of further details and explanation. There seems to be a gap between the amount of information included on the science and the amount of information given on uncertainty in most NAS. This suggests that although a lot of emphasis is placed on communicating science, communication of uncertainty is considered less important. We now move to more detailed analysis of the NAS.

\subsection{Uncertainty assessment framework}

We present our qualitative comparison of the ten NAS in Table 1. The quantitative categories (Numerical Values and Spread) in the uncertainty assessment framework show higher scores compared to the qualitative categories (Substantiation and Depth). Furthermore, the majority of the countries have the same score across the two quantitative categories showing a predominantly consistent approach in the different countries in the quantitative representation of scientific uncertainty. The Finnish and Scottish NAS achieve the highest scores in both quantitative categories as their numerical projections are very clearly presented and the potential spread/range in the numbers is well explained. Due to their preference for qualitative descriptors (e.g. mild winters and hot summers), the English and Dutch NAS score lowest in these categories.

Within the qualitative categories we notice a stark difference between the Substantiation and Depth category. The average scores for Substantiation are only marginally lower compared to the scores in the quantitative categories. Within this category, we notice that scores for Source of information and Climate scenario are highest, whereas the scores for Climate model are substantially lower. Only the German NAS achieves top scores for all three categories. All other NAS show inconsistent scores across the Substantiation categories. For the second qualitative category, Depth, we used the concept of the cascade of uncertainties to examine which sources of uncertainty are explicitly included in the NAS. Table 2 indicates how the six sources of uncertainty are covered in the NAS and the resultant average score is then included in Table 1. The NAS of Germany and Finland cover most of the sources of uncertainty but they do not do so extensively. The other eight NAS include a few sources of uncertainty at most and half of the strategies barely acknowledge uncertainty in their communication. 
Table 1 Qualitative assessment framework for the comparison of the coverage of science and uncertainty across the different NAS

\begin{tabular}{|c|c|c|c|c|c|c|c|c|c|c|}
\hline & BEL & DEN & ENG & FIN & FRA & GER & HUN & NEL & ScO & WAL \\
\hline $\begin{array}{l}\text { Numerical } \\
\text { values (NV) }\end{array}$ & $\begin{array}{l}\text { NV used in } \\
\text { main body } \\
\text { of the text }\end{array}$ & $\begin{array}{l}\text { NV used in } \\
\text { main body of } \\
\text { the text, } \\
\text { detailed table } \\
\text { on projections } \\
\text { is included }\end{array}$ & $\begin{array}{l}\text { NV only } \\
\text { given for } \\
\text { selective } \\
\text { variables }\end{array}$ & $\begin{array}{l}\text { NV used in } \\
\text { main body } \\
\text { of the text, } \\
\text { detailed } \\
\text { table on } \\
\text { projections } \\
\text { is included }\end{array}$ & $\begin{array}{l}\text { NV used in } \\
\text { main body } \\
\text { of the text }\end{array}$ & $\begin{array}{l}\text { NV used in } \\
\text { main body } \\
\text { of the text }\end{array}$ & $\begin{array}{l}\text { NV used in } \\
\text { main body of } \\
\text { the text, } \\
\text { detailed table } \\
\text { on projections } \\
\text { is included but } \\
\text { assumed } \\
\text { average global } \\
\text { warming by } \\
1^{\circ} \mathrm{C} \text { is not } \\
\text { justified }\end{array}$ & $\begin{array}{l}\text { NV only } \\
\text { given for } \\
\text { selective } \\
\text { variables }\end{array}$ & $\begin{array}{l}\text { NV included in } \\
\text { tables }\end{array}$ & $\begin{array}{l}\text { NV used in } \\
\text { main body of } \\
\text { the text but are } \\
\text { given for } \\
\text { different } \\
\text { timescales for } \\
\text { temperature } \\
\text { and } \\
\text { precipitation }\end{array}$ \\
\hline NV Score & 1 & 2 & 0 & 2 & 1 & 1 & 1 & 0 & 2 & 1 \\
\hline Spread & \begin{tabular}{|l} 
Values \\
with very \\
specific \\
uncertainty \\
ranges are \\
used but \\
not \\
explained
\end{tabular} & $\begin{array}{l}\text { Error margins } \\
\text { and ranges for } \\
\text { variables are } \\
\text { inconsistent }\end{array}$ & $\begin{array}{l}\text { No ranges } \\
\text { are given } \\
\text { for any } \\
\text { values }\end{array}$ & $\begin{array}{l}\text { Range of } \\
\text { variation } \\
\text { between the } \\
\text { minimum } \\
\text { and } \\
\text { maximum } \\
\text { value of the } \\
\text { different } \\
\text { scenarios } \\
\text { included and } \\
\text { explained }\end{array}$ & \begin{tabular}{|l|} 
Model \\
outputs for \\
two \\
regional \\
models \\
used are \\
visualised \\
$->$ spread \\
is \\
visualised, \\
confidence \\
intervals \\
explicit \\
\end{tabular} & 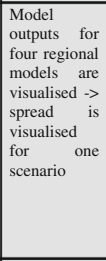 & $\begin{array}{l}\text { Mean, median } \\
\text { and standard } \\
\text { deviation are } \\
\text { stated but not } \\
\text { explained }\end{array}$ & $\begin{array}{l}\text { No ranges } \\
\text { are given } \\
\text { for any } \\
\text { values }\end{array}$ & \begin{tabular}{|l|} 
Central \\
estimates and \\
probability \\
ranges are \\
explicitly stated \\
and explained
\end{tabular} & \begin{tabular}{|l} 
Central \\
estimates and \\
probability \\
ranges \\
explicitly \\
stated for \\
some variables \\
but not \\
explained \\
where ranges \\
come from
\end{tabular} \\
\hline $\begin{array}{l}\text { Spread } \\
\text { Score }\end{array}$ & 1 & 1 & 0 & 2 & 2 & 2 & 1 & 0 & 2 & 1 \\
\hline
\end{tabular}

Substantiati-

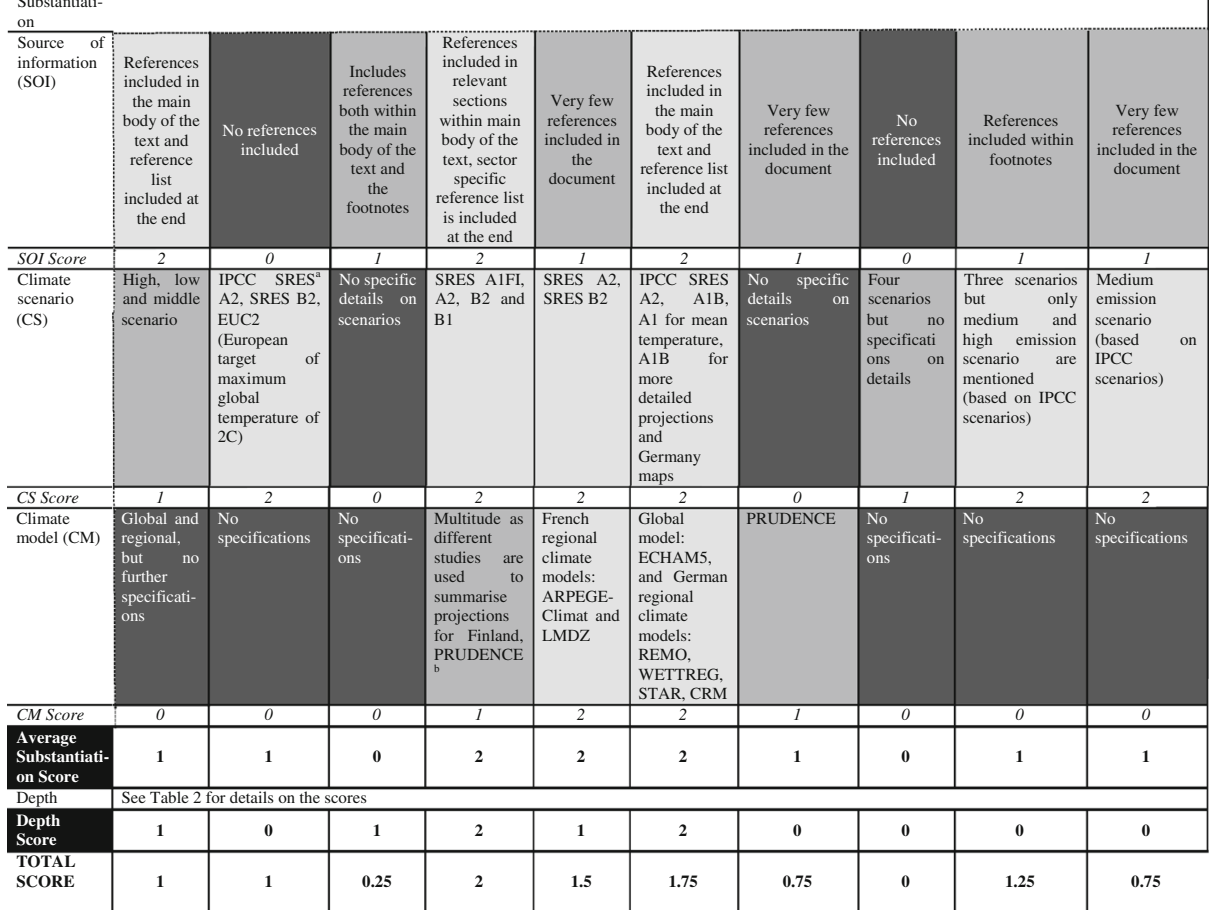

${ }^{a}$ SRES - Special Report on Emissions Scenarios

${ }^{\mathrm{b}}$ PRUDENCE - Prediction of regional scenarios and uncertainties for defining European climate change risks and effects

The most frequently mentioned sources of uncertainty are GHG emissions and climate models. This may reflect a perception that research is closer to being able to quantify uncertainty originating from these sources (e.g. Majda and Branicki 2012; Smith et al. 2009) than it is able to do so with uncertainty originating from other sources. Many NAS do not even acknowledge regional climate projections as a potential source even though there is wide agreement that they are marked by a number of uncertainties (e.g. Foley 2010; 
Table 2 The cascade of uncertainties in the NAS

\begin{tabular}{lllllllllll}
\hline & GER & FIN & FRA & BEL & ENG & DEN & NEL & SCO & WAL & HUN \\
\hline Future society & $\checkmark$ & $\checkmark \checkmark$ & & & $\checkmark$ & & & & & \\
GHG emissions & $\checkmark \checkmark$ & $\checkmark \checkmark$ & $\checkmark$ & $\checkmark$ & $\checkmark$ & & $\checkmark$ & $\checkmark$ & $\checkmark$ & \\
Climate model & $\checkmark \checkmark$ & $\checkmark \checkmark$ & $\checkmark$ & $\checkmark$ & $\checkmark$ & $\checkmark$ & $\checkmark$ & & & $\checkmark$ \\
Regional scenarios & $\checkmark \checkmark$ & $\checkmark$ & & & & & & & & \\
Impact model & $\checkmark$ & & $\checkmark$ & & & & & & & \\
Local impacts & $\checkmark \checkmark$ & $\checkmark \checkmark$ & & $\checkmark$ & & $\checkmark$ & & & & \\
Total score & 10 & 9 & 3 & 3 & 3 & 2 & 2 & 1 & 1 & 1 \\
Average score & $\mathbf{2}$ & $\mathbf{2}$ & $\mathbf{1}$ & $\mathbf{1}$ & $\mathbf{1}$ & $\mathbf{0}$ & $\mathbf{0}$ & $\mathbf{0}$ & $\mathbf{0}$ & $\mathbf{0}$ \\
\hline
\end{tabular}

\section{More detailed}

\section{Less detailed}

\section{Depth of coverage of sources of uncertainty}

The table shows the different levels of the cascade of uncertainty and gives a qualitative assessment of the inclusion/exclusion of each one in the different NAS. $\checkmark \checkmark$ type of uncertainty mentioned and some more detail/explanation given ( 2 points), $\checkmark$ type of uncertainty mentioned ( 1 point), blank cells signify that the type of uncertainty was not mentioned ( 0 points)

Stainforth et al. 2007). Furthermore, the uncertainties within the category 'Future society' encompass socio-economic uncertainties, demographic developments and technological advances, which are very difficult to predict (hence the use of scenarios) and yet are the main initial impetus into the cascade as they determine the level of GHG emissions upon which climate and resultant impact projections are based.

The results show that most NAS have shortcomings regarding the qualitative categories of assessment and perform better in quantitative terms. That is, they include quantitative values when talking about climate projections but are not explicit about where those numbers come from. There is a lack of explicitness about the underlying future socioeconomic uncertainties that will resonate throughout the cascade.

There are also marked differences between the NAS in terms of their score patterns across categories of assessment. There can be many reasons for this such as different policy frameworks and drivers, target audiences, scientific and cultural traditions, levels of knowledge and public acceptance of climate change, as well as the aim of the NAS, the stage of adaptation planning and the institutional context. We will take a first step towards exploring some of these potential influences on the communication of uncertainty within the NAS in the next section.

\section{Discussion - biases, inconsistencies and contrasting discourses}

\subsection{Biases and inconsistencies in the communication of uncertainty}

We examined the inclusion and communication of scientific uncertainty across ten European NAS and analysed the patterns between different categories in the uncertainty assessment 
framework and between countries. Our framework has also revealed salient differences in the communication of uncertainty in the different countries' NAS, reinforcing the call for a much needed more systematic communication of uncertainty (Biesbroek et al. 2010; Lourenço et al. 2009). Across all countries a bias emerges towards communicating uncertainties that are perceived to be more quantifiable at the cost of communicating more qualitative uncertainties such as future socio-economic conditions. This bias however, leads to the question of how countries can justify quantifying and communicating uncertainty further down the cascade, when those at the top are barely mentioned. Not only does this mean that an incomplete picture of uncertainties is portrayed but it also skews the attention towards those uncertainties that the strategies are explicit about. This could create a false sense of certainty where this in actual fact does not exist and direct attention to those uncertainties that are potentially not the key ones to be concerned about.

A number of factors are generally considered to influence the design of NAS such as the stage of adaptation planning (Hanger et al. 2012), the institutional setting with its dominant problem framing and the aim of the NAS (Termeer et al. 2012). As the decision about the level of communication of uncertainty is part of the design of the NAS, it could be assumed that these factors can also be used to explain the differences in the communication of uncertainty in the NAS. However, when these different factors are applied to explain the differences in our findings, our empirical data does not seem to tell the expected story.

Firstly, past research explains that according to the stage of adaptation planning there are different ways of dealing with uncertainty in different countries such as hiding, or embracing uncertainties and including uncertainties in decision-making (Hanger et al. 2012). Our framework reveals that some of these different ways of dealing with uncertainty can also be seen in the different categories in the framework with the quantitative uncertainties being more 'embraced' and the 'qualitative' uncertainties being generally more 'hidden'. Hanger et al.'s (2012) research, for example, showed that British policymakers recommend that uncertainty should be embraced in the adaptation planning process. It is surprising, therefore, that the textual communication of uncertainty in the English NAS is rather limited and seems to be in contrast with a) the statements made by the policymakers in past research and b) with the adaptation planning development stage that England is at; the UK has often been framed as being amongst those countries furthest advanced in the adaptation planning process in Europe (Juhola and Westerhoff 2011; Massey and Bergsma 2008).

A second explanation for the lack of uncertainty communication in the NAS could be that the problem framing for climate change adaptation prevalent in the institutional setting is aimed at reducing complexity (Termeer et al. 2012). Therefore, lengthy discussions of uncertainties that cannot easily be quantified could be considered as counteracting such an intention. However, even though past research found that the institutional settings in Finland, the UK and the Netherlands are all marked by a one-dimensional problem framing attitude (Termeer et al. 2012), the Finnish on the one hand and the Dutch and English NAS on the other hand are at opposite ends of the scores from our uncertainty assessment framework.

Thirdly, we could look to the differing aims of the NAS as an explanation for the difference in uncertainty communication. These aims can vary between different countries from agenda-setting to being more of a coordinating umbrella type document (Termeer et al. 2012). The German NAS for example has been described to be one of the milestones of the agenda-setting process and as a strategy for mobilisation within the country (Stecker et al. 2012). It is thus surprising to note the open treatment of uncertainty in the German NAS. The finding that openly discussing uncertainties in policy documents results in a lack of political support and financial assistance (Termeer et al. 2012) seems to stand in contrast with the aim of mobilisation. These examples, seeming contrasts and somewhat 'surprising' results show 
that the differences in uncertainty communication cannot be explained in a simple, straightforward way but instead it is necessary to take a broader view at the cultural and sociopolitical frameworks within which the NAS are conceptualised in order to achieve a richer understanding and insight.

\subsection{Contrasting discourses - an excursus}

To gain a profound understanding of the influence of the policy frameworks and drivers, socio-political contexts, and scientific and cultural traditions on the specific characteristics of the communication of uncertainties in NAS, a systematic analysis and comparison of all countries with an NAS would be needed. We will, however, only take an exploratory look at England and Germany, as a first step towards more systematic research in this direction. We chose those two countries as though neither of them is at the extreme ends of the assessment scale, they provide us with an interesting comparison and an opening for further investigation. We chose the English NAS from the UK for further analysis and comparison with the German one.

The two countries share a number of commonalities: they have often been considered leaders in climate change adaptation in Europe (Juhola and Westerhoff 2011), they are at the cutting edge of climate science, they show similarities in the agenda setting process of climate adaptation (Keskitalo et al. 2012; Stecker et al. 2012) and following the research set out by Hanger et al. (2012) they should be dealing with uncertainty in a similar fashion as their journeys along the adaptation planning path are at a similar point. Yet their NAS differ in terms of the style of communication and transparency of scientific uncertainty.

\subsubsection{The German context}

Germany has a strong tradition of environmental politics and a societal environmental consciousness that goes back to the 1980s (Beck 2012; Krueck et al. 1999). Climate change started gaining political attention in 1986 when several influential scientists framed climate change as a 'climate catastrophe' (Beck 2004; Krueck et al. 1999; Weingart et al. 2000). The German parliament established the Enquete Commission (a politico-scientific parliamentary enquiry) on 'Preventative Measures to Protect the Earth's Atmosphere' the following year quickly succeeded by a second (Beck 2004; Krueck et al. 1999; Weingart et al. 2000). These commissions involved a cross-section of stakeholders from industry, NGOs, the scientific community and politics (Beck 2004).

The Enquete Commissions first embarked on fact-finding and assimilation of the scientific evidence in order to establish a consensus on the knowledge, resonating with the German consensus-oriented political culture (Beck 2012; Krueck et al. 1999). This consensus not only legitimised the centrality of scientific expertise in the policy-making process (Beck 2012), but also stabilised and institutionalised climate change as an issue (Beck 2012; Krueck et al. 1999). The commissions managed to avoid the politicization of climate science and achieved closure on its legitimacy early on (Beck 2004; Krueck et al. 1999; Weingart et al. 2000). The Commissions also defined climate change as a research problem, which stresses scientific uncertainty inherent in the issue and influences the public discourse on the subject (Krueck et al. 1999). The Commissions ensured that scientific uncertainty was regarded as a dynamo for instant action rather than an excuse for inaction and controversy (Beck 2004). This acceptance of climate science and uncertainty related to it was mirrored in the public which hardly challenged climate science (Jasanoff 2011). The transparency and detailed treatment of uncertainty in the German NAS can thus be seen to reflect the politico- 
scientific tradition of accepting and understanding the inevitability of uncertainty in climate science.

\subsubsection{The English context}

Similarly to the German case, climate change came onto the agenda in the UK in the late 1980s with a speech by the then Prime Minister Margaret Thatcher to the Royal Society (Hulme and Turnpenny 2004). By the mid-1990s the Hadley Centre had been created and two reports outlining the impacts of climate change and possible government responses had been published (Hulme and Turnpenny 2004). The UK Climate Impacts Programme (UKCIP) was set up in 1997 and has played a leading role in adaptation nationally and internationally, inspiring others, including Germany, to follow suit (Stecker et al. 2012). Developments on the climate impacts side were followed by a report on energy and the environment in 2000 by the Royal Commission on Environmental Pollution and the National Climate Change Programme in the same year (Hulme and Turnpenny 2004) which were followed by a Government Energy White Paper in 2003 (Owens 2010). In 2008, the Climate Change Act came into force.

Though expert advice through the Royal Commission on Environmental Pollution, UKCIP, the Hadley Centre and as of 2008 the Committee on Climate Change has clearly influenced the policy making process, it remains unclear whether expert advice alone inspired the UK government action on climate change. Geopolitical factors and a desire to distance the UK from the US in climate policy have also been said to have played an important role (Owens 2010). Furthermore, although the UK was the first country to make action on climate change legally binding, political consensus on what to do about climate change in the UK remains elusive (Carter 2008). Austerity measures taken during the economic crisis have also had a significant effect on the environmental and climate change agenda in which party politics bind for public support (Carter 2008).

In many respects, the UK is leading the way with the probabilistic UKCP09 climate scenarios and the boundary work that is taking place at the science-policy interface through the UKCIP led stakeholder engagement (Tompkins et al. 2010). It thus seems surprising that the NAS does not seem to sufficiently reflect the richness of the available knowledge. While the $\mathrm{UK}$ is at the forefront of ground breaking climate research, cultural preferences continue to reside with trusting empirical observations opposed to conceptual models (Jasanoff 2011). Scientists - with some exceptions (e.g. Pall et al. 2011) - and the UK media are often reluctant to link specific weather events to climate change (Gavin et al. 2011). Thus the majority of people do not think that there is empirical evidence of climate change and its impacts (Clements 2012). In contrast, the German parliament and the German media have been explicit in making a link between extreme events and climate change (Stecker et al. 2012; Weingart et al. 2000). Although the scientific knowledge base on climate change has been importantly formed by UK scientists, model projections and associated uncertainties may not sit comfortably with a tradition of evidence-based policy making, and thus do not find a place in the English NAS but instead are left behind in the boundary space, where they can be further explored but are not in the limelight of the policy context.

\subsection{What do these two cases tell us?}

The two case studies are suggestive of the broader socio-political context within which the NAS have developed and are nested. They seem to propose that the traditions of environmental policy, the level of societal and political consensus on the credibility and salience of scientific knowledge on climate change and its associated uncertainties and the actions required, and the 
extent of politicization of climate change affect the openness and transparency of NAS regarding scientific uncertainties. Dominant framings of climate change (de Boer et al. 2010), different governance regimes (Rothstein et al. 2012), different civic epistemologies (Jasanoff 2011), and different risk management cultures also underpin differences in NAS.

What is, and importantly what is not, included with regard to information on uncertainties in the adaptation planning process is interesting and reflective of wider cultural traditions. Other factors such as the susceptibility to change, or the perceived role of the state in risk management, are also arguably important and point to the need for further research.

Both case studies point to the different styles for communicating uncertainty in England and Germany. While exploratory in nature, they do highlight:

a) similar adaptation development stages between countries do not necessarily result in similar communication approaches,

b) even if policymakers support the 'embracing' of uncertainties this does not mean that these are communicated comprehensively in the NAS and

c) the NAS may serve different functions and different audiences which will affect the level of communication of scientific uncertainty within them.

\section{Conclusion}

Our analysis has shown that there are marked differences between and within European NAS regarding the level of detail they provide on climate science and uncertainty related to it. This shows that even though these documents are defined as the same type of policydocument, different countries have very different takes on what should and should not be communicated within their NAS. This selective communication of uncertainty however, does not paint a complete picture of the actual knowledge base and could potentially create a false sense of certainty.

It can be argued that the NAS fulfil different aims and may thus differ in the level of detail and the transparency on scientific uncertainty. However, seen that the process through which the NAS are developed often happens 'behind closed doors' (Termeer et al. 2012: 9), it may be difficult to reconstruct which assumptions have been made and which uncertainties taken into account if these are not openly communicated.

European countries have called for 'structured communication about [...] uncertainties [...] to correctly develop adaptation actions' (Lourenço et al. 2009: 15). We suggest that a starting point for achieving this may be to encourage a more systematic acknowledgment and communication of uncertainties for which the uncertainty assessment framework can be used. It proved clearly useful for the classification of the different types and aspects of uncertainties communicated and provided a valuable structure against which the different NAS could be compared. The framework could help raise awareness among research users about explicit and embedded information on scientific uncertainty within documents.

By its very nature this methodology does not take into account the foundations on and the contexts within which these NAS have been developed, the available knowledge or the perception or status quo of uncertainty within adaptation decision making in these countries; nuances which could be achieved through more in-depth research. However, what this methodology enables is to use it as a diagnostic tool to highlight that the communication of scientific uncertainty is not just contingent on the stage of adaptation planning, the aim of the NAS or the institutional context within the different countries. 
Instead, there are most likely broader socio-political factors that were touched upon briefly in the two exploratory case studies that also affect how countries communicate scientific uncertainty differently.

To achieve more structured uncertainty communication it is thus not only necessary to encourage greater consistency in the acknowledgement of uncertainties for which the uncertainty assessment framework may be useful, but to compliment this with more systematic research into the impact of the broader national socio-political frameworks on this communication. This complimentary approach may help to overcome the dichotomy between the demand for more structured uncertainty communication across Europe and the realisation that different politico-scientific cultures and traditions may make it difficult to design a single European one-size-fits-all approach for communication (Beck 2012).

Acknowledgments This research has been conducted with funding from the UK Natural Environment Research Council (NERC). Suraje Dessai is supported by the UK Natural Environment Research Council (NE/H003509/1) and the European Research Council under the European Union's Seventh Framework Programme (FP7/2007 2013)/ERC Grant agreement no. 284369. Jouni Paavola acknowledges the support of the UK Economic and Social Research Council (ESRC) for the Centre for Climate Change Economics and Policy (CCCEP). We would also like to thank James Porter and the two anonymous reviewers for their helpful comments and suggestions.

Open Access This article is distributed under the terms of the Creative Commons Attribution License which permits any use, distribution, and reproduction in any medium, provided the original author(s) and the source are credited.

\section{References}

Beck S (2004) Localizing global change in Germany. In: Jasanoff S, Martello ML (eds) Earthly politics: local and global in environmental governance. MIT Press, Cambridge, $\mathrm{p}$ viii, $356 \mathrm{p}$

Beck S (2012) The challenges of building cosmopolitan climate expertise: the case of Germany. Wiley Interdiscip Rev Clim Chang 3:1-17

Biesbroek GR, Swart RJ, Carter TR, Cowan C, Henrichs T, Mela H, Morecroft MD, Rey D (2010) Europe adapts to climate change: comparing National Adaptation Strategies. Glob Environ Chang Hum Policy Dimens 20:440-450

Budescu DV, Broomell S, Por H-H (2009) Improving communication of uncertainty in the reports of the intergovernmental panel on climate change. Psychol Sci 20:299-308

Carter N (2008) Combating climate change in the UK: challenges and obstacles. Polit Q 79:194-205

Clements B (2012) Exploring public opinion on the issue of climate change in Britain. Br Polit 7:183-202

Commission of the European Communities (2009) White paper - adapting to climate change: towards a European framework for action Brussels COM (2009) 147 final \{SEC (2009) 386\} \{SEC (2009) 387\} \{SEC (2009) 388\}

Curry JA, Webster PJ (2011) Climate science and the uncertainty monster. Bull Amer Meteorol Soc 92:1667

de Boer J, Wardekker JA, van der Sluijs JP (2010) Frame-based guide to situated decision-making on climate change. Glob Environ Change Hum Policy Dimens 20:502-510

Dessai S, Hulme M (2004) Does climate adaptation policy need probabilities? Clim Policy 4:107-128

Dessai S, van der Sluijs J (2007) Uncertainty and Climate Change Adaptation - a Scoping Study. Copernicus Institute Research Institute for Sustainable Development and Innovation, Utrecht

Fischhoff B (1987) Treating the public with risk communications: a public health perspective. Sci Technol Hum Values 12:13-19

Fischhoff B (2007) Nonpersuasive communication about matters of greatest urgency: climate change. Environ Sci Technol 41:7204-7208

Fischhoff B (2011) Applying the science of communication to the communication of science. Clim Change 108:701-705

Foley AM (2010) Uncertainty in regional climate modelling: a review. Prog Phys Geogr 34:647-670 
Funtowicz SO, Ravetz JR (1990) Uncertainty and quality in science for policy. Kluwer, Dordrecht

Gavin NT, Leonard-Milsom L, Montgomery J (2011) Climate change, flooding and the media in Britain. Public Underst Sci 20:422-438

Hanger S, Pfenninger S, Dreyfus M, Patt A (2012) Knowledge and information needs of adaptation policymakers: a European study. Reg Environ Chang 1-11

Hulme M, Turnpenny J (2004) Understanding and managing climate change: the UK experience. Geogr J 170:105-115

Jasanoff S (2011) Cosmopolitan knowledge: climate science and global civic epistomology. In: Dryzek JS, Norgaard RB, Schlosberg D (eds) The oxford handbook of climate change and society. Oxford University Press, Oxford

Juhola S, Westerhoff L (2011) Challenges of adaptation to climate change across multiple scales: a case study of network governance in two European countries. Environ Sci Policy 14:239-247

Keskitalo ECH, Westerhoff L, Juhola S (2012) Agenda-setting on the environment: the development of climate change adaptation as an issue in European states. Environ Policy Gov n/a-n/a.

Krueck C, Borchers J, Weingart P (1999) Climate research and climate policy in Germany: assets and hazards of consensus-based risk management. In: Edwards PN, Miller CA (eds) Changing the atmosphere. MITY Press, Boston

Lourenço TC, Leitner M, Heinen M, Biesbroek R, Desmond M, Hohmann R (2009) Outcomes of the 1st International CIRCLE Workshop on climate change adaptation. CIRCLE ERA-Net: Climate Impact Research Coordination for a Larger Europe

Majda AJ, Branicki M (2012) Lessons in uncertainty quantification for turbulent dynamical systems. Discret Contin Dyn Syst 32:3133-3221

Massey E, Bergsma E (2008) Assessing adaptation in 29 European countries. Institute for Environmental Studies Amsterdam

Moser SC, Dilling L (2011) Communicating climate change: closing the science-action gap. In: Dryzek JS, Norgaard RB, Schlosberg D (eds) The oxford handbook of climate change and society. Oxford University Press, Oxford

Owens S (2010) Learning across levels of governance: expert advice and the adoption of carbon dioxide emissions reduction targets in the UK. Glob Environ Chang Hum Policy Dimens 20:394-401

Pall P, Aina T, Stone DA, Stott PA, Nozawa T, Hilberts AGJ, Lohmann D, Allen MR (2011) Anthropogenic greenhouse gas contribution to flood risk in England and Wales in autumn 2000. Nature 470:382-385

Pidgeon N (2012) Climate change risk perception and communication: addressing a critical moment? Risk Anal 32:951-956

Rabinovich A, Morton TA (2012) Unquestioned answers or unanswered questions: beliefs about science guide responses to uncertainty in climate change risk communication. Risk Anal 32:992-1002

Rothstein H, Borraz O, Huber M (2012) Risk and the limits of governance: exploring varied patterns of riskbased governance across Europe. Regul Gov n/a-n/a

Schneider SH (1983) CO2, climate and society: a brief overview. In: Chen RS, Boulding E, Schneider SH (eds) Social science research and climate change: an interdisciplinary appraisal. Reidel, Dordrecht, $\mathrm{p}$ viii, $255 \mathrm{p}$

Smith RL, Tebaldi C, Nychka D, Mearns LO (2009) Bayesian modeling of uncertainty in ensembles of climate models. J Am Stat Assoc 104:97-116

Stainforth DA, Allen MR, Tredger ER, Smith LA (2007) Confidence, uncertainty and decision-support relevance in climate predictions. Philos Trans R Soc A-Math Phys Eng Sci 365:2145-2161

Stecker R, Mohns T, Eisenack K (2012) Anpassung an den Klimawandel - Agenda Setting und Politikintegration in Deutschland. Zeitschrift für Umweltpolitik \& Umweltrecht 35

Swart RJ, Biesbroek GR, Binnerup S, Carter TR, Cowan C, Henrichs T, Loquen S, Mela H, Morecroft MD, Reese M, Rey D (2009) Europe adapts to climate change: comparing National Adaptation Strategies. Partnership for European Environmental Research Helsinki

Termeer C, Biesbroek R, van der Brink M (2012) Institutions for adaptation to climate change: Comparing National Adaptation Strategies in Europe. Eur Polit Sci 11(1):41-53

Tompkins EL, Adger WN, Boyd E, Nicholson-Cole S, Weatherhead K, Arnell N (2010) Observed adaptation to climate change: UK evidence of transition to a well-adapting society. Global Environ Chang-Hum Policy Dimens 20:627-635

van der Sluijs J, Craye M, Funtowicz S, Kloprogge P, Ravetz J, Risbey J (2005a) Experiences with the NUSAP system for multidimensional uncertainty assessment. Water Sci Technol 52:133-144

van der Sluijs JP, Craye M, Funtowicz S, Kloprogge P, Ravetz J, Risbey J (2005b) Combining quantitative and qualitative measures of uncertainty in model-based environmental assessment: the NUSAP system. Risk Anal 25:481-492

Weingart P, Engels A, Pansegrau P (2000) Risks of communication: discourses on climate change in science, politics, and the mass media. Public Underst Sci 9:261-283

Wilby RL, Dessai S (2010) Robust adaptation to climate change. Weather 65:180-185 